Article

\title{
An Improved Quantum-Behaved Particle Swarm Optimization Method for Economic Dispatch Problems with Multiple Fuel Options and Valve-Points Effects
}

\author{
Qun Niu ${ }^{1, *}$, Zhuo Zhou ${ }^{1}$, Hong-Yun Zhang ${ }^{1}$ and Jing Deng ${ }^{2}$
}

1 Shanghai Key Laboratory of Power Automation Technology, School of Mechatronics Engineering and Automation, Shanghai University, Shanghai 200072, China;

E-Mails: zhouzhuo1101@yahoo.com.cn (Z.Z.); zhanghongyun@shu.edu.cn (H.-Y.Z.)

2 Intelligent Systems and Control Group, School of Electronics, Electrical Engineering and Computer Science, Queen's University of Belfast, Belfast BT9 5AH, UK; E-Mail: jdeng01@qub.ac.uk

* Author to whom correspondence should be addressed; E-Mail: comelycc@hotmail.com; Tel./Fax: +86-21-56334241.

Received: 2 July 2012; in revised form: 10 August 2012 / Accepted: 22 August 2012 /

Published: 19 September 2012

\begin{abstract}
Quantum-behaved particle swarm optimization (QPSO) is an efficient and powerful population-based optimization technique, which is inspired by the conventional particle swarm optimization (PSO) and quantum mechanics theories. In this paper, an improved QPSO named SQPSO is proposed, which combines QPSO with a selective probability operator to solve the economic dispatch (ED) problems with valve-point effects and multiple fuel options. To show the performance of the proposed SQPSO, it is tested on five standard benchmark functions and two ED benchmark problems, including a 40-unit ED problem with valve-point effects and a 10-unit ED problem with multiple fuel options. The results are compared with differential evolution (DE), particle swarm optimization (PSO) and basic QPSO, as well as a number of other methods reported in the literature in terms of solution quality, convergence speed and robustness. The simulation results confirm that the proposed SQPSO is effective and reliable for both function optimization and ED problems.
\end{abstract}

Keywords: economic dispatch; quantum-behaved particle swarm optimization; valve-point effects; multiple fuel options 


\section{Introduction}

Economic dispatch (ED) is considered to be one of the key functions in electric power system operation. The main objective of ED is to determine the optimal scheduling of power outputs for all generating units that minimizes the total fuel cost while satisfying all the equality and inequality constraints of units and system. Due to valve-point effects, prohibited operating zones and multiple fuel effects, the characteristics of power generating units are inherently highly nonlinear [1].

Multiple fuel options problem (coal, nature gas or oil) is one of the important kinds of ED problems and each part of the hybrid cost function implies some information about the fuel being burned or the operation cost of units. Taking valve-point effects and multiple fuel options into consideration, the ED problem can be represented as a non-smooth optimization problem, which causes difficulties in finding the global or near global optimization solution using conventional approaches.

Over the past two decades, many modern meta-heuristic methods have been applied to ED problems, such as genetic algorithm (GA) [2], particle swarm optimization (PSO) [3], differential evolution (DE) [4], ant colony optimization (ACO) [5] and simulated annealing (SA) [6]. Among these methods, PSO has recently attracted more attention due to its rapid convergence and algorithmic accuracy compared with other optimization methods.

PSO is a population based optimization algorithm, which was introduced by Kennedy and Eberhart in 1995 [7]. PSO is motivated by the simulation of social behaviour of animals such as fish schooling and bird flocking. In the conventional PSO mechanism, a swarm of individuals (called particles) fly within the search space. Each particle represents a potential solution to the optimization problem. The position of a particle is influenced by the best position (pbest) found by itself (i.e., its own experience) and the position of the best particle in the whole swarm (gbest) (i.e., the experience of neighbouring particles).

Although PSO can converge quickly towards the optimal solution, it has difficulties in reaching a global optimum and suffers from premature convergence. Moreover, PSO has several control parameters. The convergence of the algorithm depends heavily on the value of its control parameters.

Taking advantage of both PSO mechanism and quantum mechanics, in 2004, a new version of PSO, quantum-behaved particle swarm optimization, named QPSO, was proposed by Sun, Xu and Feng [8], which is inspired by quantum mechanics and trajectory analysis of PSO. As a quantum system is an uncertain system that is different from classical stochastic system in which every particle can appear at any position with a certain probability, the swarm can search in the whole feasible region [9]. Besides, unlike PSO, there are no velocity vectors for particles in QPSO, and it has fewer parameters to be adjusted, which makes it easier to implement. In [10-12], convergence analysis and other varients of QPSO have been presented. As an efficient algorithm, QPSO has been applied to many optimization problems, such as system identification [13], non-linear programming problems [14], power system [15], etc. Although Coelho et al. proposed a quantum-inspired HQPSO using the harmonic oscillator potential well to solve economic dispatch problems [16], Sun and Lu applied QPSO to ED problems [15], and Chakraborty et al. presented a hybrid QPSO to solve the ED problems [17], to the best of our knowledge, it has not been used yet to solve ED problems with multiple fuel options.

In this paper, an improved QPSO namely SQPSO is proposed to solve ED problems with multiple fuel options and valve-points effects. In the proposed SQPSO, a new selective probability operator is 
introduced into the updating mechanism of QPSO, which can balance the global and local searching abilities and enhance the diversity of QPSO. In particular, based on the selective probability operator, pbest and gbest are used to generate the local attractor of QPSO, with user defined selective probability, to enhance the local search performance. This modification on the original QPSO together with a recombination operator will maintain the best information of the swarm and, in the same time, exchange information between individuals to increase the population diversity.

To show the performance of the proposed SQPSO, five popular benchmark functions and two ED problems with valve-point effects and multi-fuel options are tested. The results obtained by SQPSO are analyzed and compared with PSO, DE and QPSO, as well as some other optimization methods reported in recent literature. The remainder of this paper is organized as follows: Section 2 is the formulation of the ED problem and Section 3 presents the conventional PSO, QPSO and proposed SQPSO, respectively. Section 4 gives the experimental results. Finally, Section 5 concludes the paper.

\section{Formulation of the ED Problem}

The main objective of solving the ED problem is to minimize the total fuel cost of each thermal generating unit in electric power system while satisfying a variety of equality and inequality constraints. The total fuel cost function of ED problem is described as:

$$
\min F_{T}=\sum_{i=1}^{n} F_{i}\left(P_{i}\right)
$$

where $F_{T}$ is the total generation cost, $n$ is the total number of generating unit, $P_{i}$ is the power of the $i$ th generator and $F_{i}$ is its corresponding fuel cost, which is defined by the following equation as:

$$
F_{i}\left(P_{i}\right)=a_{i}+b_{i} P_{i}+c_{i} P_{i}^{2}
$$

where $a_{i}, b_{i}$ and $c_{i}$ are the cost coefficients and subject to:

$$
\begin{gathered}
\sum_{i=1}^{n} P_{i}=P_{D}, i=1,2, \ldots \ldots ., n \\
P_{i}^{\min }<P_{i}<P_{i}^{\max }
\end{gathered}
$$

where $P_{D}$ is the total demand of the power system, $P_{i}^{\min }$ and $P_{i}^{\max }$ are the minimum and maximum output of the $i$ th generation unit, respectively.

\subsection{The ED Problem with Valve-Point Effects}

A valve-point is the rippling effect added to the generation unit curve when each steam admission valve in a turbine starts to open [2]. This curve poses higher order non-linearity and discontinuity, which makes the problem of finding the optimum more difficult and increases the number of local minima in the fuel cost function. Considering the valve-point effects, sinusoidal functions are added to the quadratic cost function, which is defined by the following equation:

$$
F_{i}\left(P_{i}\right)=a_{i}+b_{i} P_{i}+c_{i} P_{i}^{2}+\left|e_{i} \sin \left(f_{i}\left(P_{i}^{\min }-P_{i}\right)\right)\right|
$$

where $e_{i}, f_{i}$ are the coefficients of generator $i$, reflecting the valve-point. 


\subsection{ED Problem with Multiple Fuels and Valve-Point Effects}

To give a more accurate description of the ED problem, the effects of multiple fuels resources (coal, nature gas or oil) should also be considered. Each segment of the hybrid cost function implies some information about the fuel being burned or the unit's operation. Since the dispatching units are practically supplied with multi-fuel sources, each unit should be represented with several piecewise quadratic functions reflecting the effects of fuel type changes, and the generator must identify the most economic fuel to burn [2]. The number of non-differentiable points in the objective function increases when multiple fuels are taken into consideration. The incremental cost functions of a generator with multi-fuel options are illustrated in Figure 1. The ED problems with both multiple and fuels valve-point effects can be represented as follows:

$$
F_{i}\left(P_{i}\right)= \begin{cases}a_{i 1}+b_{i 1} P_{i}+c_{i 1} P_{i}^{2}+\left|e_{i 1} \sin \left(f_{i 1}\right)\left(P_{i 1}^{\min }-P_{i 1}\right)\right|, & \text { fuel } 1, P_{i}^{\min }<P_{i}<P_{i 1} \\ a_{i 2}+b_{i 2} P_{i}+c_{i 2} P_{i}^{2}+\left|e_{i 2} \sin \left(f_{i 2}\right)\left(P_{i 2}^{\min }-P_{i 2}\right)\right|, & \text { fuel } 2, P_{i 1}<P_{i}<P_{i 2} \\ a_{i k}+b_{i k} P_{i}+c_{i k} P_{i}^{2}+\left|e_{i 2} \sin \left(f_{i k}\right)\left(P_{i k}^{\min }-P_{i k}\right)\right|, & \text { fuel } k, P_{i k-1}<P_{i}<P_{i}^{\max }\end{cases}
$$

Figure 1. Incremental cost function of a generator with multi-fuel options.

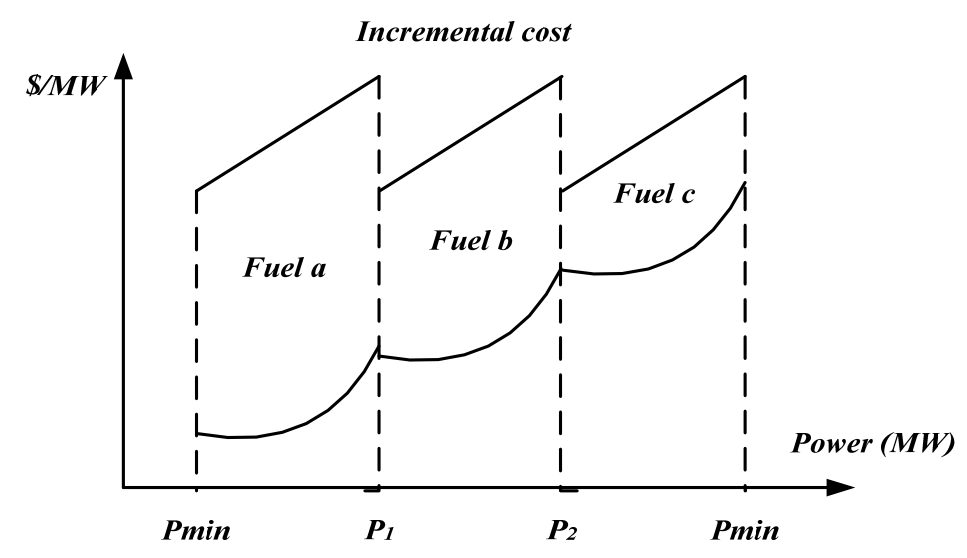

\section{The Proposed SQPSO Algorithm}

\subsection{Conventional Particle Swarm Optimization}

PSO is a population-based stochastic optimization algorithm, which is inspired by the social intelligence and movements of fishes or birds in the swarm. In PSO, each potential solution is a point in the search space and is called as 'particle'. Each particle is assumed to have two characteristics: a position and a velocity. The target of the particles is to find the best result of the objective function. Initially, a population of particles is randomly generated within the search space. At each iteration, it stores memory of best position of each individual and best position of the whole population. By taking advantages of the particles' own experience and experience of its neighbours, the particles could fly towards the optimal solution.

For example, in a $n$-dimensional search space, the position and velocity of an individual $i$ are represented as the vectors: $X_{i}=\left(X_{i 1}, X_{i 1}, \ldots, X_{i n}\right)$ and $V_{i}=\left(V_{i 1}, V_{i 2}, \ldots, V_{i n}\right)$. The best position for each particle is denoted as: pbest $_{i}=\left(\right.$ pbest $_{1 i}$, pbest $t_{2 i}, \ldots$, pbest $\left._{n i}\right)$ and gbest $_{i}$ is the best solution found in the 
whole swarm. In standard PSO, the position and velocity of particles are updated by the following equations:

$$
\begin{gathered}
V_{i}^{(t+1)}=w \times V_{i}^{(t)}+c_{1} \times \operatorname{rand}() \times\left(\text { pbest }_{i}-x_{i}^{(t)}\right)+c_{2} \times \operatorname{rand}() \times\left(\text { gbest }_{i}-x_{i}^{(t)}\right) \\
x_{i}^{(t+1)}=x_{i}^{t}+v_{i}^{(t+1)}
\end{gathered}
$$

where:

$x_{i}^{t}$ and $v_{i}^{t}$ represent the position and velocity of individual $i$ at generation $t$;

$w$ is the inertia weight parameter that controls the momentum of particles;

$c_{1}$ and $c_{2}$ are positive constants, which balance the need for local and global search;

$\operatorname{rand}()$ is a random number between 0 and 1 .

\subsection{Quantum-Behaved Particle Swarm Optimization}

In the conventional PSO, a particle moves in the search space by the moments of its position and velocity. In the quantum model of a PSO, the state of a particle is depicted by wave function $\Psi(x, t)[8]$, instead of position and velocity. QPSO introduces the mean best position into the algorithm and uses a strategy based on a quantum delta potential well model to sample around the previous best points Furthermore, QPSO has only one parameter, which is easier to control than PSO algorithm. Employing the Monte Carlo method, particles are updated according to the following equations:

$$
\left\{\begin{array}{c}
x_{i j}(t+1)=p_{i j}(t)+\beta * \operatorname{Mbest}_{i j}(t)-x_{i j}(t) * \operatorname{In}(1 / u), \text { if } k \geq 0.5 \\
x_{i j}(t+1)=p_{i j}(t)-\beta * \operatorname{Mbest}_{i j}(t)-x_{i j}(t) * \operatorname{In}(1 / u), \text { if } k<0.5
\end{array}\right.
$$

The following gives the explication of the update Equation (9):

(1) $x_{i j}(t+1)$ is denoted as the position of the $j$ th dimension of the $i$ th particle for the next generation $t+1$.

(2) $P_{i j}(t)$ is the local attractor to make sure SQPSO can converge, which is defined as follows:

$$
p_{i j}=\phi * \text { Pbest }_{i j}+(1-\phi) * \text { gbest }_{j}
$$

where $\phi$ is a random number uniformly distributed in $(0,1)$; Mbest $t_{i j}$ is a global point, which can be calculated by the mean of the Pbest of all particles in the population. The definition is given is as follows:

$$
\operatorname{Mbest}_{i j}(t)=\left(\frac{1}{N} \sum_{i=1}^{N} \text { Pbest }_{i 1}(t-1), \frac{1}{N} \sum_{i=1}^{N} \operatorname{Pbest}_{i 2}(t-1), \ldots, \frac{1}{N} \sum_{i=1}^{N} \operatorname{Pbest}_{i n}(t-1)\right)
$$

where $N$ represents the population size and Pbest $t_{i}$ is the best position of the $i$ th particle.

(3) In this paper, $\beta$ is called the constriction-expansion coefficient, and it is linearly decreasing when the iteration increases:

$$
\beta^{t}=\beta_{\max }-\frac{\beta_{\max }-\beta_{\min }}{i t N u m} * t
$$

where itNum is the maximum iteration number, $t$ is the current iteration number $\beta_{\max }=1.0$ and $\beta_{\min }=0.5$.

(4) $u$ and $k$ are two random numbers uniformly distributed in $(0,1)$. 


\subsection{The Proposed Quantum-Behaved Particle Swarm Optimization}

In the original QPSO, the local attractor is calculated by Equation (10), which means that the $P_{i j}(t)$ is a random position between the individual best position and the group best position. However, the drawback is the difficulty in maintaining the best information of the swarm, especially when the optimal solution is at the boundary of the problem. In [18], Jong-Bae Park proposed an improved PSO, which introduced a kind of crossover operation. In this operation, particles update the position with the exchange information of previous generation particle position and the individual best position of itself. In this paper, a modified QPSO is proposed, called SQPSO, which introduces a selective probability operator into the update mechanism when calculating the local attractor $P_{i j}(t)$. In SQPSO, the information of global best position and the whole swarm's individual best position are used to update the position for the next generation. The reason behind the inclusion of the selective probability operator is to enable the use of recombination operator into the original QPSO which will help to maintain the best solution and, at the same time, exchange information between individuals in the whole swarm. The pseudo code for the proposed selective probability operator is given in Figure 2 .

Figure 2. The pseudo code for the proposed crossover operator of SQPSO.

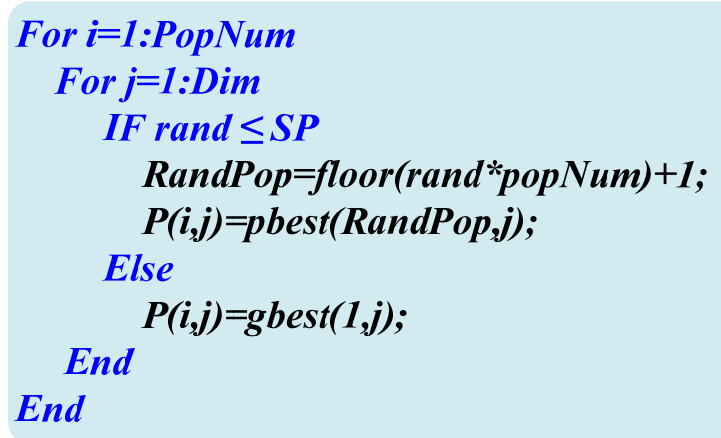

In Figure 2, PopNum is the number of population and Dim is the Dimensionality for each individual. RandPop is an individual randomly selected from the swarm. SP is the selective probability, which can control whether the local attractor $P(i, j)$ is generated from individual best position or global best position. If rand $\leq S P$, then the local attractor $P(i, j)$ will select its value from the Pbest of the individual RandPop and if rand $>S P$, then the value of $P(i, j)$ will select the point of global best position. Using the $S P, P(i, j)$ can not only make use of the previous best swarm information but also increase the population diversity and consequently enhance the global search ability. The principle of the modification is illustrated in Figure 3 and the procedure of the proposed SQPSO is described as follows:

(1) Initialize the population, which are generated randomly within the minimum and maximum output of each generator, using the following equations:

$$
\begin{gathered}
\text { population }=\left[\begin{array}{c}
X_{1} \\
X_{2} \\
\ldots \\
X_{n}
\end{array}\right] \\
X_{i}=\left[x_{i, 1,} x_{i, 2}, \ldots, x_{i, n}\right], x_{i j}=P_{i j}^{\min }+\operatorname{rand} *\left(P_{i j}^{\max }-P_{i j}^{\min }\right)
\end{gathered}
$$


where $X_{i}$ is the $i t h$ individual of the population, $\left(x_{i j}\right.$ is the $j$ th data vector of $i t h$ individual; $P_{i j}^{\min }$ and $P_{i j}^{\max }$ are the maximum and minimum output limit values of the $j$ th control variable.

Figure 3. Principle of the modified of SQPSO.

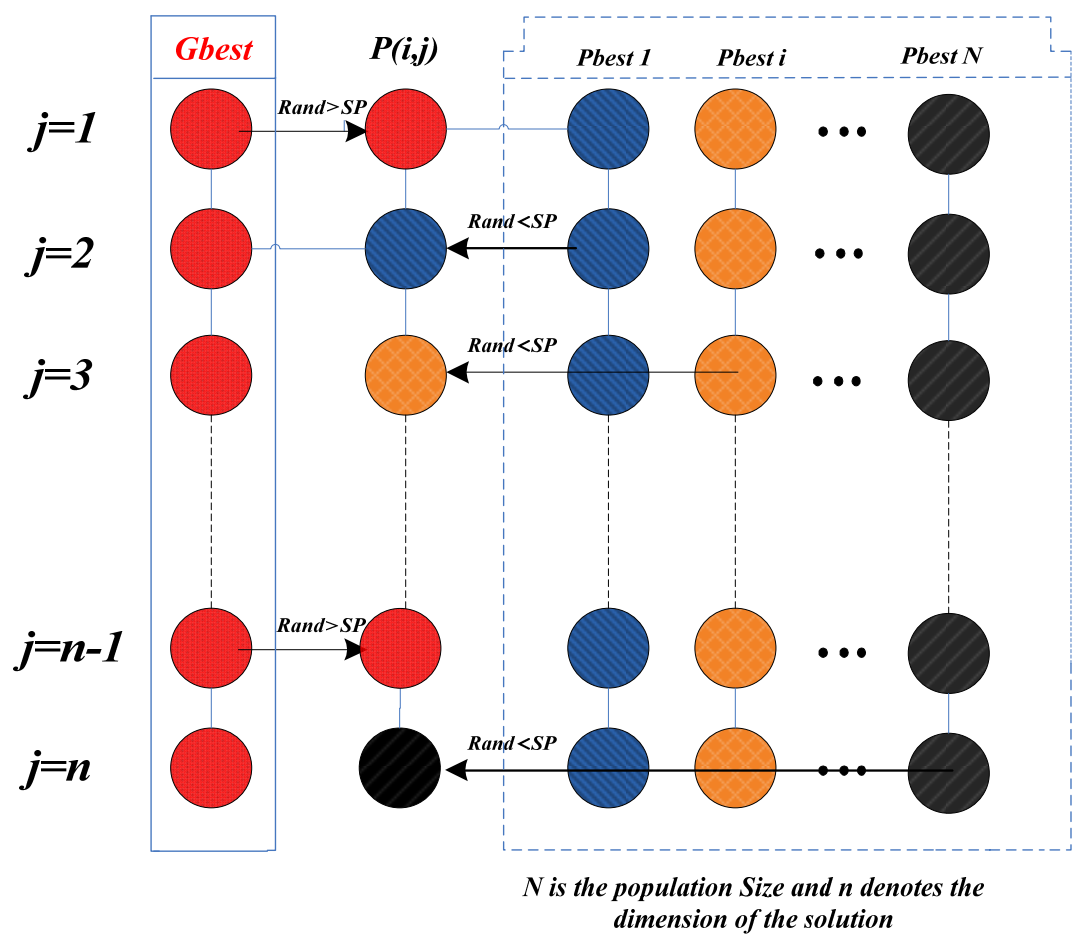

For the multi-fuel ED problem, the relationship between unit output and fuel type is shown in Figure 4, taking a 10-generator problem as an example, each unit has its minimum and maximum output of generation and the sum of the whole power output should satisfy the total output demand, and as shown in Figure 4, different range of unit output corresponds to different type of fuel.

Figure 4. Relationship between unit output and fuel type.

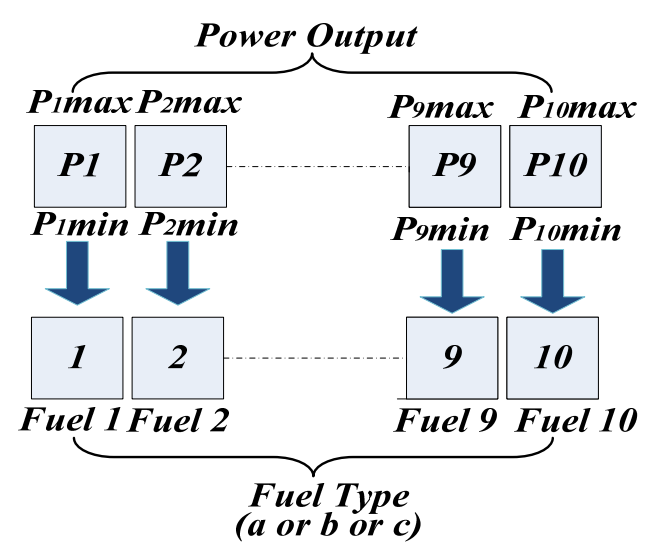

(2) Constraint handling for real power balance. Since the individuals of the population are created randomly and with the evolution of particles, newly generated individual may violate the constraints. Therefore, it is important to keep all the individual variables within their feasible ranges. Hence, the following procedure is adopted by the SQPSO to modify the value of new generated variables to satisfy the power balance constraint. 


$$
x_{i j}=\left\{\begin{array}{cc}
P_{i j}^{\min } & \text { if } x_{i j} \leq P_{i j}^{\min } \\
P_{i j}^{\max } & \text { if } x_{i j}>P_{i j}^{\min } \\
x_{i j} & \text { otherwise }
\end{array}\right.
$$

The amount of power balance violation is calculated by:

$$
p d=\sum_{i=1}^{n} P_{i}-P_{D}
$$

if $p d=0$, go to step 3; if $p d \neq 0$, the value of $p d$ will be adjusted by allocating it to the output of a unit, which is chosen randomly from the whole set of generating units, so that the generating constraints can be satisfied. If the output of the chosen unit goes outside the feasible boundaries, its value should be modified using Equation (14). The constraints handling procedure is illustrated in Figure 5.

Figure 5. Procedure of constraint handling of the SQPSO algorithm.

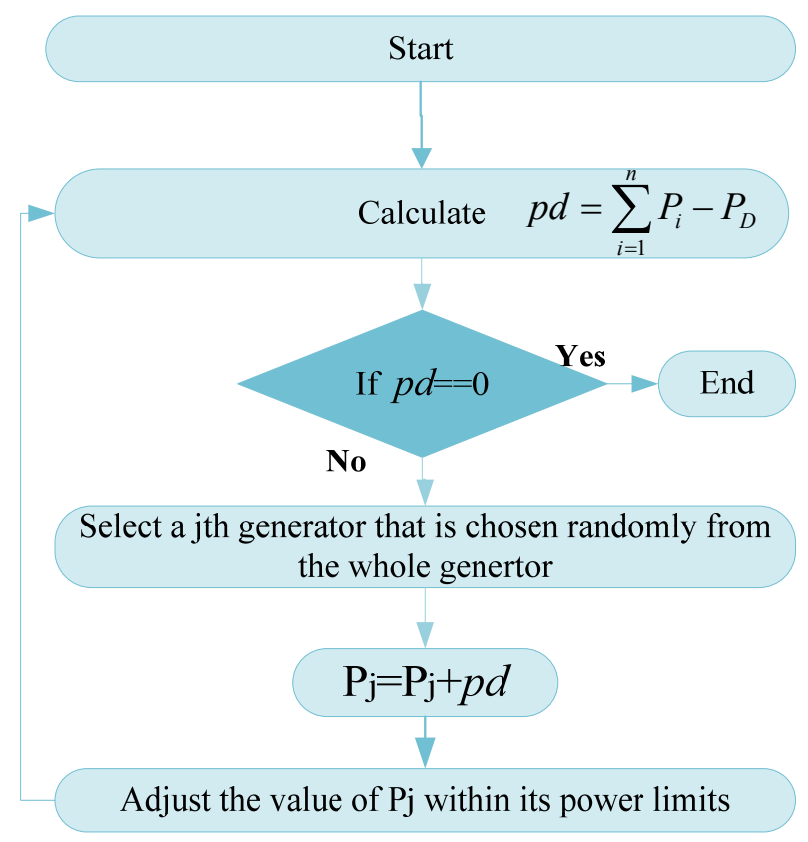

(3) Parameter setting. There are two parameters in SQPSO, one is the constriction-expansion coefficient which decreases from 1.0 to 0.5 linearly. Another parameter is the introduced selective probability $(S P)$. In this paper, the SP for SQPSO increases from 0.5 to 0.8 linearly using the following equation:

$$
S P^{t}=S P_{\max }-\frac{S P_{\max }-S P_{\min }}{i t N u m} * t
$$

where $S P^{t}$ is the value of $\mathrm{SP}$ at iteration t. $S P_{\max }$ and $S P_{\min }$ are maximum and minimum selective probability. At the early stage, the population will select more vectors from the group best position, which can accelerate the convergence speed. As the iteration number increases, the population will draw more vectors from the individual best positions to enhance the diversity of the whole swarm.

(4) Evaluate the objective function value of each particle. 
(5) Update pbest. Compare each particle's objective function value with its pbest. If the current value is better than the pbest value, set the pbest value to the current value.

(6) Update gbest. Determine best gbest of the swarm as the minimum pbest of all particles.

(7) Calculate the Mbest, constriction-expansion coefficient $\beta$ according to Equation (11) and Equation (12), respectively.

(8) Calculate the local attractor according to the Selective probability operator proposed in this paper.

(9) Update the particle's position using Equation (9)

(10) Check if the stop criterion satisfied?

(11) If not, then go to step 2.

(12) Else, the searching process is stopped.

\section{Experimental Results}

\subsection{Benchmark Functions}

To verify the performance of the proposed SQPSO, five benchmark functions (Sphere, Jason, Griewank, Rosenbrock and Rastrigrin) listed in Table 1 are conducted. These functions are all minimization problems with the minimum value to be zero. The results produced by the proposed SQPSO are compared with that of the EGA, DPSO, HPSO, IPSO and IQPSO in [17]. EGA is a modified genetic algorithm with elitism and adaptive mutation probability control, and DPSO, HPSO, IPSO are three types of revised version of PSO. IQPSO is an improved quantum-inspired particle swarm optimization, which is based on the principle of quantum rotation gates. Additionally, three algorithms are also used in this paper for comparison, which are PSO, DE and QPSO. For PSO, the acceleration coefficients $\mathrm{c} 1$ and $\mathrm{c} 2$ are set to 2, and the inertia weight decreased from 0.9 to 0.4 linearly [19]. The parameter of $\mathrm{DE}$ is set to $\mathrm{F}=0.4, \mathrm{CR}=0.8$ [20].

Table 1. Benchmark functions.

\begin{tabular}{lcccc}
\hline Name & Function & Dim & Range & Opt \\
\hline Sphere & $f_{1}(x)=\sum_{i=1}^{n} x_{i}^{2}$ & 40 & {$[-100,100]$} & 0 \\
Jason & $f_{2}(x)=\sum_{i=1}^{n}\left(x_{i}-i\right)^{2}$ & 40 & {$[-100,100]$} & 0 \\
Griewank & $f_{3}(x)=\frac{1}{4000} \sum_{i=1}^{n} x_{i}^{2}-\prod_{i=1}^{n} \cos \left(\frac{x_{i}}{\sqrt{i}}\right)+1$ & 40 & {$[-600,600]$} & 0 \\
Rosenbrock & $f_{4}(x)=\sum_{i=1}^{n}\left[100\left(x_{i+1}-x_{i}^{2}\right)^{2}+\left(x_{i}-1\right)^{2}\right]$ & 40 & {$[-2.048,2.048]$} & 0 \\
Rastrigrin & $f_{5}(x)=\sum_{i=1}^{n}\left[x_{i}^{2}-10 \cos \left(2 \pi x_{i}\right)+10\right]$ & 40 & {$[-5.12,5.12]$} & 0 \\
\hline
\end{tabular}

For QPSO and SQPSO, the coefficient $\beta$ decreases from 1.0 to 0.5 linearly and the selective probability (SP) for SQPSO increases from 0.5 to 0.8 linearly. To compare the solution quality and convergence characteristics, 50 independent trial runs are performed for each benchmark function and 
mean function value and best function value are recorded. In order to make a fair comparison, the population size is set to 80 and population dimension is 40 for all the five benchmark functions. The maximum iteration number is set to 5000. All the algorithms are implemented in MATLAB 2008a and executed on an Intel Core2 Duo $1.66 \mathrm{GHz}$ personal computer.

The numerical results in Table 2 show that the proposed SQPSO can achieve satisfactory performance. Specifically, both the sphere and Jason function have only one single optimal solution, so it is usually introduced to test the local search ability of the algorithm. From the results, it can be seen that the SQPSO outperforms all the other algorithms in terms of mean function value and best function value, which indicates SQPSO has strong local search ability. Rosenbrock is a mono-modal function and its optimal solution lies in a narrow area. The experimental results on Rosenbrock show that the mean function value of SQPSO is better than DPSO, HPSO, IPSO, PSO and QPSO. However, the best function value is inferior to other algorithms reported in [21]. Griewank and Rastrigrin are both multi-modal and they are usually used to compare the global search ability of the algorithm. As to Griewank, SQPSO can hit the minimum value zero and the mean function value is superior to other algorithms too. For Rastrigrin, both EGA and IQPSO give a better performance than SQPSO and the results of SQPSO are better than other methods.

Table 2. Mean value and best value for five benchmark functions with different approaches.

\begin{tabular}{|c|c|c|c|c|c|}
\hline Algorithm & $\begin{array}{l}f_{1}(\text { Sphere) } \\
\text { Mean (Best) }\end{array}$ & $\begin{array}{c}f_{2} \text { (Jason) } \\
\text { Mean (Best) }\end{array}$ & $\begin{array}{c}\boldsymbol{f}_{3}(\text { Griewank) } \\
\text { Mean (Best) }\end{array}$ & $\begin{array}{c}f_{4}(\text { Rosenbrock) } \\
\text { Mean (Best) }\end{array}$ & $\begin{array}{c}f_{5} \text { (Rastrigrin) } \\
\text { Mean (Best) }\end{array}$ \\
\hline EGA [11] & $\begin{array}{c}2.743 \times 10^{-10} \\
(0)\end{array}$ & $\begin{array}{c}8.865 \times 10^{-8} \\
\left(3.748 \times 10^{-22}\right)\end{array}$ & $\begin{array}{c}1.042 \times 10^{-4} \\
\left(7.952 \times 10^{-13}\right)\end{array}$ & $\begin{array}{c}0.84 \\
\left(6.537 \times 10^{-4}\right)\end{array}$ & $\begin{array}{c}2.257 \\
\left(6.537 \times 10^{-4}\right)\end{array}$ \\
\hline DPSO [11] & $\begin{array}{c}5.403 \times 10^{-7} \\
\left(4.532 \times 10^{-14}\right)\end{array}$ & $\begin{array}{c}2.595 \times 10^{-6} \\
\left(1.173 \times 10^{-12}\right)\end{array}$ & $\begin{array}{c}1.322 \times 10^{-3} \\
\left(2.167 \times 10^{-10}\right)\end{array}$ & $\begin{array}{c}28.094 \\
\left(1.150 \times 10^{-2}\right)\end{array}$ & $\begin{array}{c}28.826 \\
(19.899)\end{array}$ \\
\hline HPSO [11] & $\begin{array}{c}1.319 \times 10^{-6} \\
\left(2.824 \times 10^{-10}\right)\end{array}$ & $\begin{array}{c}6.735 \times 10^{-3} \\
\left(1.503 \times 10^{-10}\right)\end{array}$ & $\begin{array}{c}2.546 \times 10^{-3} \\
\left(5.136 \times 10^{-9}\right)\end{array}$ & $\begin{array}{c}28.995 \\
\left(2.346 \times 10^{-2}\right)\end{array}$ & $\begin{array}{c}29.956 \\
(15.393)\end{array}$ \\
\hline IPSO [11] & $\begin{array}{c}1.524 \times 10^{-7} \\
\left(3.406 \times 10^{-11}\right)\end{array}$ & $\begin{array}{c}1.350 \times 10^{-5} \\
\left(2.107 \times 10^{-10}\right)\end{array}$ & $\begin{array}{c}2.224 \times 10^{-3} \\
\left(1.454 \times 10^{-10}\right)\end{array}$ & $\begin{array}{c}27.13 \\
\left(2.339 \times 10^{-2}\right)\end{array}$ & $\begin{array}{c}31.906 \\
(15.064)\end{array}$ \\
\hline IQPSO [11] & $\begin{array}{c}1.085 \times 10^{-23} \\
(0)\end{array}$ & $\begin{array}{c}2.078 \times 10^{-23} \\
(0)\end{array}$ & $\begin{array}{c}3.221 \times 10^{-7} \\
(0)\end{array}$ & $\begin{array}{c}2.19 \times 10^{-2} \\
\left(2.717 \times 10^{-9}\right)\end{array}$ & $\begin{array}{c}0.521 \\
\left(1.075 \times 10^{-4}\right)\end{array}$ \\
\hline PSO & $\begin{array}{c}2.885 \times 10^{-21} \\
\left(1.774 \times 10^{-23}\right)\end{array}$ & $\begin{array}{l}1.4526 \times 10^{-21} \\
\left(4.413 \times 10^{-24}\right)\end{array}$ & $\begin{array}{c}8.0215 \times 10^{-3} \\
(0)\end{array}$ & $\begin{array}{c}56.1057 \\
(12.4904)\end{array}$ & $\begin{array}{c}34.6046 \\
(20.8941)\end{array}$ \\
\hline $\mathrm{DE}$ & $\begin{array}{r}1.3727 \times 10^{-47} \\
\left(3.9244 \times 10^{-49}\right)\end{array}$ & $\begin{array}{c}1.0097 \times 10^{-30} \\
(0)\end{array}$ & $\begin{array}{c}3.4506 \times 10^{-4} \\
(0)\end{array}$ & $\begin{array}{l}12.4830 \\
(6.6779)\end{array}$ & $\begin{array}{c}56.7802 \\
(14.9244)\end{array}$ \\
\hline QPSO & $\begin{array}{c}5.054 \times 10^{-26} \\
\left(7.333 \times 10^{-31}\right)\end{array}$ & $\begin{array}{c}5.3011 \times 10^{-30} \\
(0)\end{array}$ & $\begin{array}{l}8.1 \\
(0)\end{array}$ & $\begin{array}{c}48.4957 \\
(25.2717)\end{array}$ & $\begin{array}{c}25.7895 \\
(13.9294)\end{array}$ \\
\hline SQPSO & $\begin{array}{r}6.5759 \times 10^{-74} \\
\left(1.8122 \times 10^{-89}\right)\end{array}$ & $\begin{array}{l}\text { (0) } \\
\text { (0) }\end{array}$ & $\begin{array}{c}2.217 \times 10^{-7} \\
(0)\end{array}$ & $\begin{array}{l}32.68016 \\
(14.7115) \\
\end{array}$ & $\begin{array}{l}13.7105 \\
(3.9798)\end{array}$ \\
\hline
\end{tabular}

In addition, compared with original QPSO without selective probability operator, the proposed SQPSO demonstrates good performance for all the five benchmark functions in terms of both the mean function value and best function value, which indicates that the SQPSO is an effective modification of QPSO. 


\subsection{ED Problem with Valve-Point Effects}

A large-scale power system of 40-generating units with quadratic cost function and valve-point effects is being considered here. Transmission losses are ignored and the total load demand of this text system is 10,500 MW. The system data can be found from [1]. One hundred independent runs are made for each method and population size is set to 80 . The stopping criterion is set to 500 . The result obtained from SQPSO is compared with some methods in the literature including IFEP [1], GA_PS_SQP [22], PC-PSO [23], SOH_PSO [23], NPSO [24] ,NPSO_LRS [24], PSO-GM [25], CBPSO_RVM [25], ICA-PSO [26], ACO [5], APSO(2) [27], HDE [28], ST-HDE [28] and IQPSO [29]. In addition, in order to compare the performance of the crossover operation in [18] with the proposed selective probability operator. The crossover operation [18] is introduced into QPSO, namely CQPSO, and the performance of CQPSO can be seen in the following results. The comparison results of SQPSO with other methods reported in literature are given in Table 3. The best solution of the SQPSO is $121,434.41 \$ / \mathrm{H}$, which is comparatively superior to most of the methods and the mean cost is better than other methods as well.

Table 3. Comparison results for ED problem with valve-point effects (40-unit system).

\begin{tabular}{lcccc}
\hline \multirow{2}{*}{ Methods } & \multicolumn{3}{c}{ Generation cost(\$/H) } & Standard \\
& Minimum & Mean & Maximum & Deviation \\
\hline IFEP [1] & $122,624.35$ & 123,382 & $125,740.63$ & NR \\
GA-PS-SQP [22] & $121,458.14$ & 122,039 & NR & NR \\
PC-PSO [23] & $121,767.90$ & $122,461.30$ & $122,867.55$ & NR \\
SOH-PSO [23] & $121,501.14$ & $121,853.57$ & $122,446.3$ & NR \\
NPSO [24] & $121,704.74$ & $122,221.37$ & $122,995.10$ & NR \\
NPSO-LRS [24] & $121,664.43$ & $122,209.32$ & $122,981.59$ & NR \\
PSO-GM [25] & $121,845.98$ & $122,398.38$ & $123,219.22$ & 258.44 \\
CBPSO-RVM [25] & $121,555.32$ & $122,281.14$ & $123,094.98$ & 259.99 \\
ICA-PSO [26] & $121,422.17$ & $121,428.14$ & $121,453.56$ & NR \\
ACO [5] & $121,532.41$ & $121,606.45$ & $121,679.64$ & 45.58 \\
APSO(2) [27] & $121,663.52$ & $122,153.67$ & $122,912.40$ & NR \\
HDE [28] & $121,813.26$ & $122,705.66$ & NR & NR \\
ST-HDE [28] & $121,698.51$ & $122,304.30$ & NR & NR \\
IQPSO [21] & $121,448.21$ & $122,225.07$ & NR & NR \\
FCASO [30] & $121,516.47$ & $122,082.59$ & NR & NR \\
CASO [30] & $121,865.63$ & $122,100.74$ & NR & NR \\
CPSO-SQP [31] & $121,458.54$ & $122,028.16$ & NR & NR \\
CPSO [31] & $121,865.23$ & $122,100.87$ & NR & NR \\
DE & $121,805.56$ & $122,142.97$ & $122,466.75$ & 151.88 \\
PSO & $121,956.18$ & $122,459.36$ & $122,785.73$ & 209.12 \\
QPSO & $121,487.27$ & $121,750.48$ & $121,991.99$ & 111.68 \\
CQPSO & $121,463.39$ & $121,732.98$ & $121,778.74$ & 79.38 \\
SQPSO & $\mathbf{1 2 1 , 4 3 4 . 4 1}$ & $\mathbf{1 2 1 , 7 2 3 . 2 2}$ & $\mathbf{1 2 1 , 8 8 1 . 5 1}$ & $\mathbf{1 0 4 . 2 9}$ \\
\hline
\end{tabular}

The convergence characteristics of the SQPSO in comparison with PSO, DE, QPSO are shown in Figure 6. It is shown that PSO converges fastest among these methods while it suffers the premature 
convergence. Besides, DE is the slowest among the four methods, as DE involves a series of mutation, crossover and greedy selection operators, which leads to low convergence speed and increases the computational time as well. QPSO and SQPSO converge at nearly the same speed, however the SQPSO can produce a better solution as iteration increases, which indicates stronger searching ability. In addition, compared with CQPSO, SQPSO can outperform it almost in all aspects, which indicates that the proposed elective probability operator is improved compared with the crossover operation in [18].

Figure 6. Convergence characteristics for total generation costs (40-uint system).

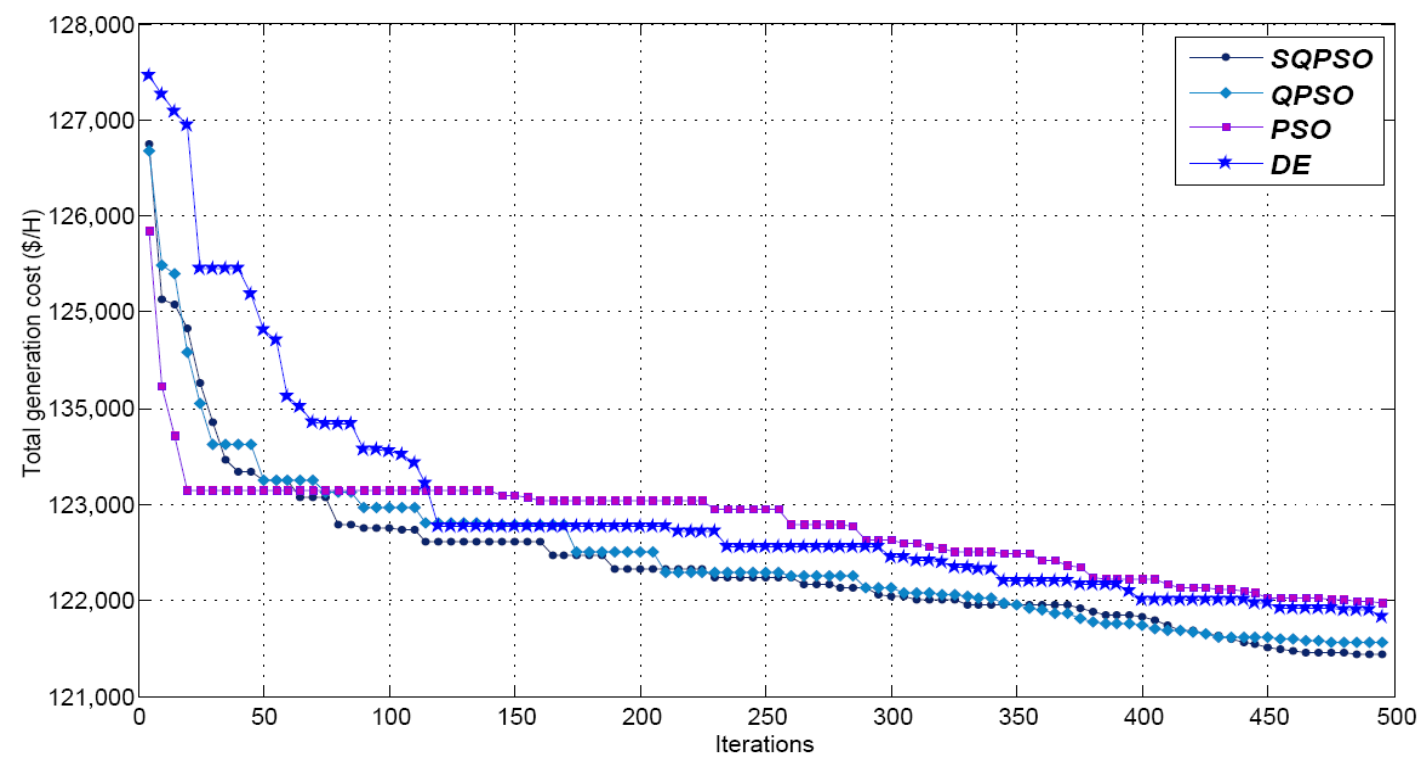

The distribution of generation costs of the four algorithms for 100 runs is shown in Figure 7 which reflects the robustness of each algorithm. The curve of the SQPSO is at the bottom of the figure and stabilizes at a relatively intensive region, which means the distribution of the solution of SQPSO is much better than other methods. The detailed results of the best solution of DE, PSO, QPSO and SQPSO, for ED problem with valve-point effects are given in Table 4.

Figure 7. Distribution of generation costs of the four algorithms for 100 runs (40-unit system).

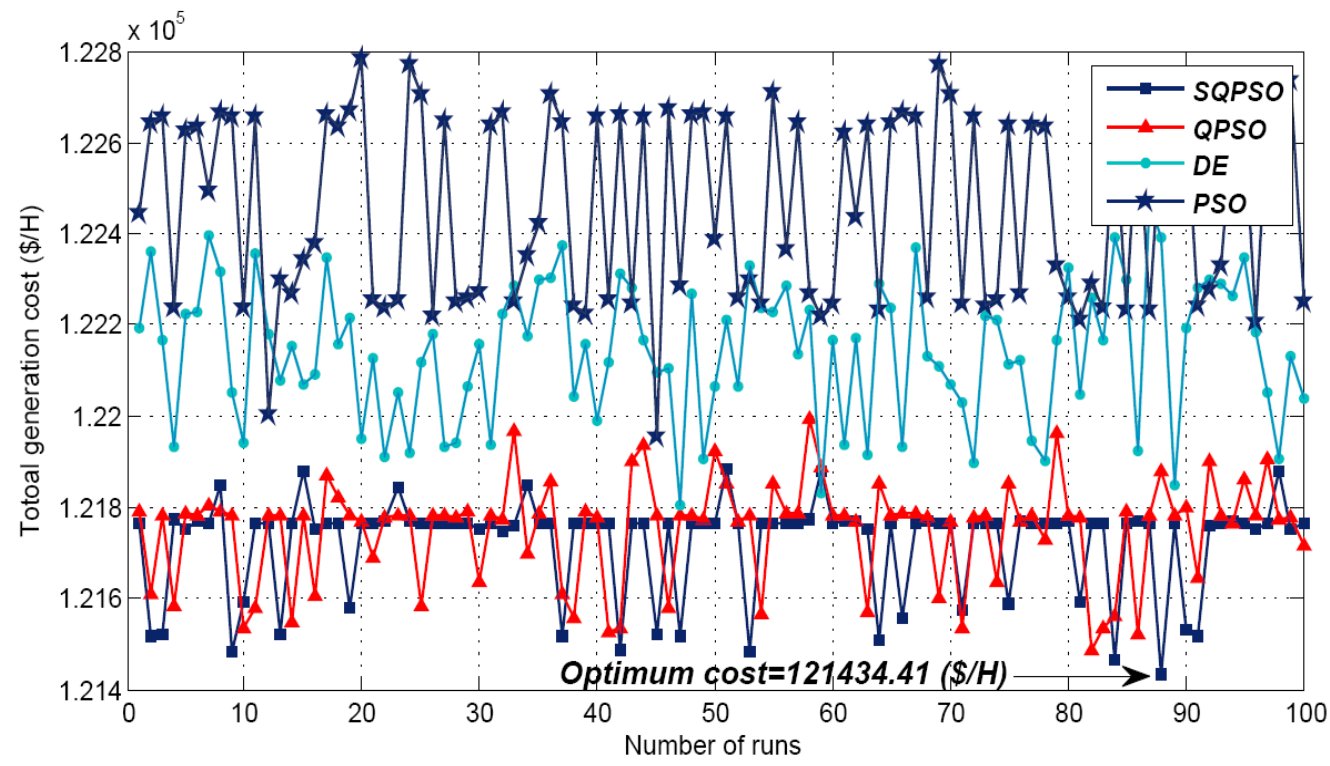


Table 4. Detailed results of the best solution of DE, PSO, QPSO and SQPSO, for ED problem with valve-point effects (40-unit system).

\begin{tabular}{|c|c|c|c|c|c|}
\hline \multirow{2}{*}{ Unit } & \multicolumn{5}{|c|}{ Methods } \\
\hline & DE & PSO & QPSO & CQPSO & SQPSO \\
\hline$P_{1}$ & 111.8012 & 113.9945 & 113.6426 & 113.9999 & 110.9173 \\
\hline$P_{2}$ & 111.5734 & 110.9343 & 111.9581 & 113.9999 & 111.7807 \\
\hline$P_{3}$ & 95.79661 & 100.748 & 97.56082 & 120.0000 & 97.56128 \\
\hline$P_{4}$ & 182.4958 & 179.1588 & 179.7457 & 179.7333 & 179.7005 \\
\hline$P_{5}$ & 87.27856 & 97.0000 & 88.53738 & 96.9999 & 93.37496 \\
\hline$P_{6}$ & 140.0000 & 140.0000 & 139.9981 & 140.0000 & 139.9862 \\
\hline$P_{7}$ & 300.0000 & 300.0000 & 299.989 & 300.0000 & 259.8548 \\
\hline$P_{8}$ & 285.2077 & 300.0000 & 284.9879 & 299.9999 & 284.9466 \\
\hline$P_{9}$ & 286.9856 & 299.9040 & 284.7968 & 293.3932 & 284.5976 \\
\hline$P_{10}$ & 130.0000 & 130.0000 & 130.0093 & 130.0000 & 130.0493 \\
\hline$P_{11}$ & 94.25143 & 94.0000 & 94.02522 & 94.0000 & 168.807 \\
\hline$P_{12}$ & 94.61699 & 94.0000 & 94.0286 & 94.0000 & 94.00315 \\
\hline$P_{13}$ & 125.7718 & 125.0000 & 125.0323 & 125.0000 & 214.7713 \\
\hline$P_{14}$ & 393.1819 & 393.9392 & 394.2728 & 394.2794 & 394.2986 \\
\hline$P_{15}$ & 395.1001 & 394.1116 & 394.2987 & 394.2794 & 304.61 \\
\hline$P_{16}$ & 393.7253 & 304.3765 & 394.3071 & 304.5196 & 394.2632 \\
\hline$P_{17}$ & 487.6391 & 500.0000 & 489.3179 & 489.2794 & 489.363 \\
\hline$P_{18}$ & 491.819 & 490.6004 & 489.2953 & 489.2795 & 489.5688 \\
\hline$P_{19}$ & 512.8806 & 513.8928 & 511.3082 & 511.2794 & 511.2797 \\
\hline$P_{20}$ & 511.7995 & 514.1406 & 511.3473 & 511.2794 & 511.3193 \\
\hline$P_{21}$ & 524.2502 & 524.3505 & 523.3044 & 523.2796 & 523.2616 \\
\hline$P_{22}$ & 523.9075 & 523.4735 & 523.3182 & 523.2796 & 523.3642 \\
\hline$P_{23}$ & 519.8336 & 529.2841 & 523.3638 & 523.2796 & 523.2587 \\
\hline$P_{24}$ & 527.6248 & 547.3133 & 523.3677 & 550.0000 & 523.3996 \\
\hline$P_{25}$ & 523.9776 & 522.9096 & 523.2928 & 523.2795 & 523.2836 \\
\hline$P_{26}$ & 523.2693 & 524.9206 & 523.3083 & 523.2798 & 523.2817 \\
\hline$P_{27}$ & 10.3912 & 10.0000 & 10.01133 & 10.0000 & 10.00975 \\
\hline$P_{28}$ & 10.0000 & 10.0000 & 10.08587 & 10.0000 & 10.0344 \\
\hline$P_{29}$ & 10.0335 & 10.0000 & 10.00228 & 10.0000 & 10.00645 \\
\hline$P_{30}$ & 92.73803 & 91.53567 & 90.21066 & 96.9999 & 88.52085 \\
\hline$P_{31}$ & 187.1519 & 190.0000 & 189.9984 & 190.0000 & 189.9972 \\
\hline$P_{32}$ & 189.9415 & 190.0000 & 189.9968 & 190.0000 & 189.9834 \\
\hline$P_{33}$ & 189.4094 & 190.0000 & 189.9988 & 190.0000 & 189.9822 \\
\hline$P_{34}$ & 197.3705 & 199.9374 & 199.9794 & 199.9999 & 165.321 \\
\hline$P_{35}$ & 199.2062 & 198.4492 & 199.9942 & 200.0000 & 199.9666 \\
\hline$P_{36}$ & 198.9157 & 200.0000 & 199.9942 & 200.0000 & 200.0000 \\
\hline$P_{37}$ & 109.5043 & 110.0000 & 110.0000 & 110.0000 & 110.0000 \\
\hline$P_{38}$ & 110.0000 & 110.0000 & 109.9926 & 110.0000 & 109.9984 \\
\hline$P_{39}$ & 108.1849 & 110.0000 & 109.9915 & 110.0000 & 109.992 \\
\hline$P_{40}$ & 512.3655 & 512.0254 & 511.3299 & 511.2794 & 511.2849 \\
\hline Total Demand & 10,500 & 10,500 & 10,500 & 10,500 & 10,500 \\
\hline Total Cost & $121,805.5647$ & $121,956.1827$ & $121,487.2762$ & $121,463.3942$ & $121,434.4071$ \\
\hline
\end{tabular}




\subsection{The ED Problem with Multi-Fuel Option and Valve-Point Effects}

In this section, the proposed SQPSO is applied to multi-fuel economic dispatch problem with valve-point effects. Transmission losses are ignored and system date can be found in [29]. The experimental results are also compared with other algorithms reported in literature, including CGA_MU [2], IGA_MU [2], ACO [5], ED-DE [32], ARCGA [33], PSO-GM [25], NPSO [24], NPSO-LRS [24], PSO-GM [25], CBPSO-RVM [25], APSO [27], GA [34], DSPSO-TSA [34], which are given in Table 5 .

Table 5. Comparison of calculation results for multiple fuel ED problems with total demand of 2700 (MW).

\begin{tabular}{|c|c|c|c|c|c|}
\hline \multirow{2}{*}{ Methods } & \multicolumn{3}{|c|}{ Generation cost $(\$ / H)$} & \multirow{2}{*}{$\begin{array}{l}\text { Standard } \\
\text { Deviation }\end{array}$} & \multirow{2}{*}{$\begin{array}{l}\text { Average } \\
\text { CPU times }\end{array}$} \\
\hline & Minimum & Mean & Maximum & & \\
\hline CGA_MU [2] & 624.7193 & 627.6087 & 633.8652 & NR & 26.64 \\
\hline IGA_MU [2] & 624.5178 & 625.8692 & 630.8705 & NR & 7.32 \\
\hline $\mathrm{ACO}[5]$ & 623.9000 & 624.3500 & 624.7800 & NR & 8.35 \\
\hline ED-DE [32] & 623.8290 & 623.8807 & 623.8894 & NR & NR \\
\hline ARCGA [33] & 623.8281 & 623.8495 & 623.8814 & NR & NR \\
\hline NPSO [24] & 624.1624 & 625.2180 & 627.4237 & NR & NR \\
\hline NPSO-LRS [24] & 624.1273 & 624.9985 & 626.9981 & NR & NR \\
\hline PSO-GM [25] & 624.3050 & 624.6749 & 625.0854 & 0.1580 & NR \\
\hline CBPSO-RVM [25] & 623.9588 & 624.0816 & 624.2930 & 0.0576 & NR \\
\hline APSO [27] & 624.0145 & 624.8185 & 627.3049 & NR & 0.52 \\
\hline GA [34] & 624.5050 & 624.7419 & 624.8169 & 0.1005 & 18.3 \\
\hline TSA [34] & 624.3078 & 635.0623 & 624.8285 & 1.1593 & 9.71 \\
\hline DSPSO-TSA [34] & 623.8375 & 623.8625 & 623.9001 & 0.0106 & 3.44 \\
\hline $\mathrm{DE}$ & 623.9280 & 624.0068 & 624.0653 & 0.0271 & 0.625 \\
\hline PSO & 624.0120 & 624.2055 & 624.4376 & 0.0889 & 0.308 \\
\hline QPSO & 623.8766 & 623.9639 & 624.4163 & 0.0688 & 0.315 \\
\hline CQPSO & 623.8476 & 623.8652 & 623.8885 & 0.0151 & 0.318 \\
\hline SQPSO & 623.8319 & 623.8440 & 623.8605 & 0.0107 & 0.324 \\
\hline
\end{tabular}

It can be seen that SQPSO can get a minimum generation cost of $623.8319(\$ / H)$, which is the best solution among all the methods. For the mean cost, SQPSO outperforms most of the methods expect for the ARCGA, which is slightly better than SQPSO, however the CUP times of ARCGA is almost three times that of SQPSO. When considering the average CPU time, the computational time for PSO, QPSO and SQPSO are at the same level, while the results of SQPSO is better than the other two methods. The detailed results of the best solution of DE, PSO, QPSO, CQPSO and SQPSO, for the multiple fuel ED problem with total demand of $2700 \mathrm{MW}$ is given in Table 6 . 
Table 6. Detailed results of the best solution of DE, PSO, QPSO and SQPSO, for multiple fuel ED problem with total demand of $2700 \mathrm{MW}$.

\begin{tabular}{ccccccccccc}
\hline & \multicolumn{2}{c}{ CQPSO } & \multicolumn{2}{c}{ DE } & \multicolumn{2}{c}{ PSO } & \multicolumn{2}{c}{ QPSO } & \multicolumn{2}{c}{ SQPSO } \\
\cline { 2 - 10 } Unit & $\begin{array}{c}\text { Output } \\
(\mathbf{M W})\end{array}$ & $\begin{array}{c}\text { Fuel } \\
\text { type }\end{array}$ & $\begin{array}{c}\text { Output } \\
(\mathbf{M W})\end{array}$ & $\begin{array}{c}\text { Fuel } \\
\text { type }\end{array}$ & $\begin{array}{c}\text { Output } \\
\text { (MW) }\end{array}$ & $\begin{array}{c}\text { Fuel } \\
\text { type }\end{array}$ & $\begin{array}{c}\text { Output } \\
\text { (MW) }\end{array}$ & $\begin{array}{c}\text { Fuel } \\
\text { type }\end{array}$ & $\begin{array}{c}\text { Output } \\
\text { (MW) }\end{array}$ & $\begin{array}{c}\text { Fuel } \\
\text { type }\end{array}$ \\
\hline$P_{1}$ & 217.567 & 2 & 220.8058 & 2 & 220.8058 & 2 & 218.587 & 2 & 218.5939 & 2 \\
$P_{2}$ & 211.7117 & 1 & 211.7154 & 1 & 211.7154 & 1 & 210.4723 & 1 & 211.2166 & 1 \\
$P_{3}$ & 279.6489 & 1 & 280.7032 & 1 & 280.7032 & 1 & 280.7087 & 1 & 281.6653 & 1 \\
$P_{4}$ & 240.5800 & 3 & 239.7713 & 3 & 239.7713 & 3 & 239.3708 & 3 & 238.9676 & 3 \\
$P_{5}$ & 276.3749 & 1 & 277.2203 & 1 & 277.2203 & 1 & 279.6347 & 1 & 279.9345 & 1 \\
$P_{6}$ & 239.6394 & 3 & 238.9671 & 3 & 238.9671 & 3 & 240.7144 & 3 & 239.2363 & 3 \\
$P_{7}$ & 290.0985 & 1 & 289.0121 & 1 & 289.0121 & 1 & 290.1244 & 1 & 287.7275 & 1 \\
$P_{8}$ & 240.8488 & 3 & 240.175 & 3 & 240.175 & 3 & 239.6396 & 3 & 239.6394 & 3 \\
$P_{9}$ & 427.6622 & 3 & 425.4145 & 3 & 425.4145 & 3 & 423.8487 & 3 & 427.1502 & 3 \\
$P_{10}$ & 275.8686 & 1 & 276.2151 & 1 & 276.2151 & 1 & 276.8994 & 1 & 275.8686 & 1 \\
\hline $\boldsymbol{P d}$ & 2,700 & 2,700 & 2,700 & 2,700 & 2,700 \\
Total Cost & 623.8476 & 623.928 & 624.012 & 623.8766 & 623.8319 \\
\hline
\end{tabular}

The convergence characteristics and the distribution of generation costs of the SQPSO in comparison with PSO, DE, QPSO are shown in Figures 8 and 9. Clearly, SQPSO converges to the optimal solution faster than other three methods. It can reach the optimal region only in a few iterations, which shows powerful global search ability.

Figure 8. Convergence characteristics for total generation costs (multiple fuel options system).

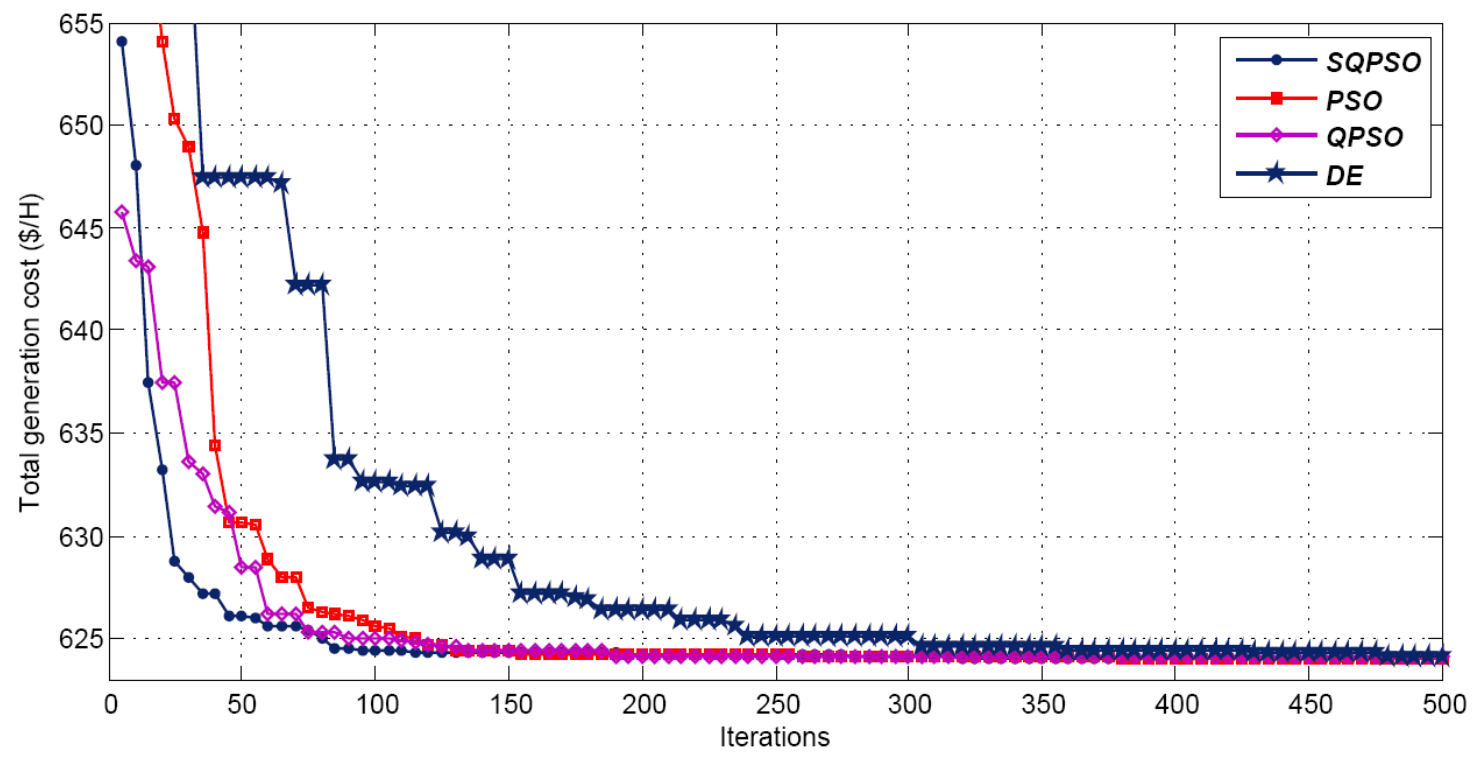


Figure 9. Distribution of generation costs for 100 runs (multiple fuel options system).

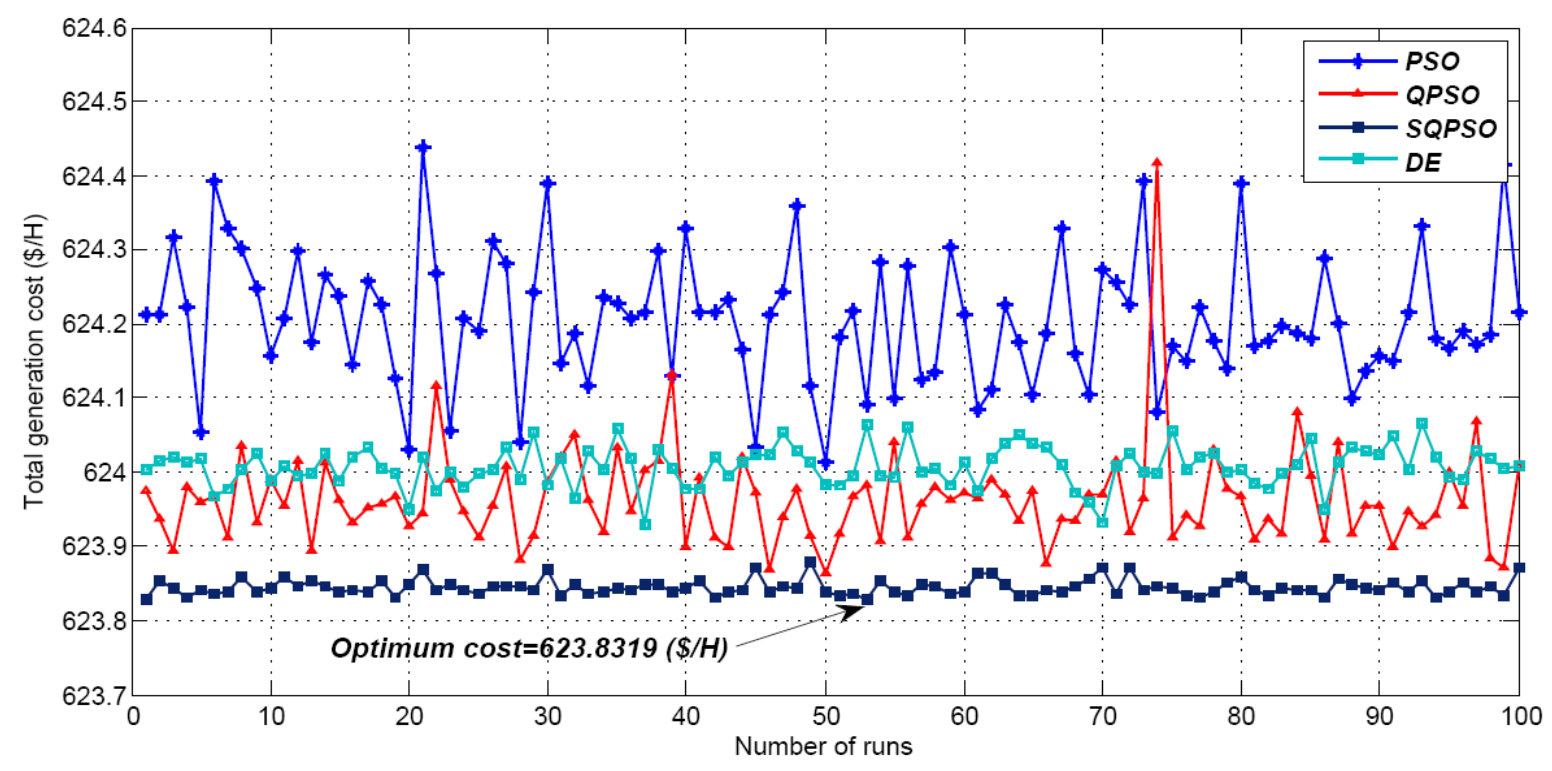

The results of different methods for the multiple fuel ED problems with total demand range from 2400 to $2600 \mathrm{MW}$ are summarized in Table 7. It again shows that the SQPSO outperforms all the other methods.

Table 7. Comparison of calculation results for multiple fuel ED problem with total demand range from 2400-2600 MW.

\begin{tabular}{|c|c|c|c|c|c|c|}
\hline \multirow{2}{*}{ Demand } & \multirow{2}{*}{ Method } & \multicolumn{3}{|c|}{ Generation cost $(\$ / \mathbf{H})$} & \multirow{2}{*}{$\begin{array}{l}\text { Standard } \\
\text { Deviation }\end{array}$} & \multirow{2}{*}{$\begin{array}{l}\text { Average } \\
\text { CPU times }\end{array}$} \\
\hline & & Minimum & Mean & Maximum & & \\
\hline \multirow{5}{*}{2400} & $\mathrm{DE}$ & 481.9030 & 481.9527 & 482.0231 & 0.0285 & 0.4781 \\
\hline & PSO & 482.0807 & 484.1717 & 491.5540 & 2.5598 & 0.3625 \\
\hline & QPSO & 481.9235 & 483.4540 & 492.6059 & 2.2612 & 0.3562 \\
\hline & CQPSO & 481.7469 & 481.7711 & 481.7974 & 0.0180 & 0.3683 \\
\hline & SQPSO & 481.7320 & 481.7440 & 481.7591 & 0.0068 & 0.3390 \\
\hline \multirow{5}{*}{2500} & $\mathrm{DE}$ & 526.4154 & 526.4771 & 526.5379 & 0.0244 & 0.5156 \\
\hline & PSO & 526.4849 & 527.5594 & 535.1762 & 1.3761 & 0.3578 \\
\hline & QPSO & 526.3758 & 527.5720 & 534.9611 & 1.4797 & 0.3328 \\
\hline & CQPSO & 526.2537 & 526.2839 & 526.3229 & 0.0187 & 0.3453 \\
\hline & SQPSO & 526.2447 & 526.2556 & $\mathbf{5 2 6 . 2 8 9 7}$ & 0.0079 & 0.3500 \\
\hline \multirow{5}{*}{2600} & $\mathrm{DE}$ & 574.5489 & 574.6371 & 574.9653 & 0.0916 & 0.5984 \\
\hline & PSO & 574.6194 & 576.0185 & 589.1900 & 2.5451 & 0.3515 \\
\hline & QPSO & 574.5857 & 575.7198 & 589.1281 & 2.0467 & 0.3315 \\
\hline & CQPSO & 574.4492 & 574.6538 & 574.7928 & 0.1439 & 0.3576 \\
\hline & SQPSO & 574.3866 & 574.5076 & 574.7659 & 0.1640 & 0.3484 \\
\hline
\end{tabular}

\section{Conclusions}

An improved quantum-behaved particle swarm optimization called SQPSO is proposed in this paper, which introduces selective probability operator into the basic QPSO. The proposed SQPSO has 
been tested on five classic benchmark functions, as well as two ED problems with valve-point effects and multiple fuel options. It shows superior optimization performance in terms of the convergence rate and the robustness, compared with DE, PSO, CQPSO and QPSO. Additionally, SQPSO also shows competitive ability over other algorithms from the literature.

\section{Acknowledgments}

This work is supported by the National Natural Science Foundation of China (61273040), Shanghai Rising-Star Program (12QA1401100), Key Project of Science and Technology Commission of Shanghai Municipality (10JC1405000), the project of Shanghai Municipal Education Commission (12YZ020) and RCUK funded Science Bridge project.

\section{References}

1. Sinha, N.; Chakrabarti, R.; Chattopadhyay, P.K. Evolutionary programming techniques for economic load dispatch. IEEE Trans. Evolut. Comput. 2003, 7, 83-94.

2. Chiang, C.L. Improved genetic algorithm for power economic dispatch of units with valve-point effects and multiple fuels. IEEE Trans. Power Syst. 2005, 20, 1690-1699.

3. Park, J.B.; Lee, K.S.; Shin, J.R. A particle swarm optimization for economic dispatch with non-smooth cost functions. IEEE Trans. Power Syst. 2005, 20, 34-42.

4. Balamurugan, R.; Subramanian, S. Hybrid integer coded differential evolution-dynamic programming approach for economic load dispatch with multiple fuel options. Energy Convers. Manag. 2008, 49, 608-614.

5. Pothiya, S.; Ngamroo, I.; Kongprawechnon, W. Ant colony optimisation for economic dispatch problem with non-smooth cost functions. Int. J. Electr. Power Energy Syst. 2010, 32, 478-487.

6. Basu, M. A simulated annealing-based goal-attainment method for economic emission load dispatch of fixed head hydrothermal power systems. Electr. Power Energy Syst. 2005, 27, 147-153.

7. Kennedy, J.; Eberhart, R. Particle Swarm Optimization. In Proceedings of the IEEE International Conference on Neural Networks Proceedings, Perth, WA, Australia, 27 November-1 December 1995; pp. 1942-1948.

8. Sun, J.; Xu, W.B.; Feng, B. A Global Search Strategy of Quantum-Behaved Particle Swarm Optimization. In Proceedings of the IEEE Conference on Cybernetics and Intelligent Systems, Singapore, 1-3 December 2004; pp. 111-116.

9. Fang, W. A review of quantum-behaved particle swarm optimization. IETE Tech. Rev. 2010, 27, 336-348.

10. Sun, J.; Wu, X.J.; Palade, V.; Fang, W.; Lai, C.-H.; Xu, W.B. Convergence analysis and improvements of quantum-behaved particle swarm optimization. Inf. Sci. 2012, 193, 81-103.

11. Sun, J.; Fang, W.; Palade, V.; Wu, X.J.; Xu, W.B. Quantum-behaved particle swarm optimization with Gaussian distributed local attractor point. Appl. Math. Comput. 2011, 218, 3763-3775.

12. Sun, J.; Fang, W.; Wu, X.J.; Palade, V.; Xu, W.B. Quantum-behaved particle swarm optimization: Analysis of the individual particle's behavior and parameter selection. Evolut. Comput. 2012, 20, 349-393. 
13. Luitel, B.; Venayagamoorthy, G.K. Particle swarm optimization with quantum infusion for system identification. Eng. Appl. Artif. Intell. 2010, 23, 635-649.

14. Sun, J.; Liu, J.; Xu, W. Using quantum-behaved particle swarm optimization algorithm to solve non-linear programming problems. Int. J. Comp. Math. 2007, 84, 261-272.

15. Sun, C.F.; Lu, S.F. Short-term combined economic emission hydrothermal scheduling using improved quantum-behaved particle swarm optimization. Expert Syst. Appl. 2010, 37, 4232-4241.

16. Leandro dos, S.C.; Viviana, C.M. Particle swarm approach based on quantum mechanics and harmonic oscillator potential well for economic load dispatch with valve-point effects. Energy Convers. Manag. 2008, 49, 3080-3085.

17. Chakraborty, S.; Senjyu, T.; Yona, A.; Saber, A.Y.; Funabashi, T. Solving economic load dispatch problem with valve-point effects using a hybrid quantum mechanics inspired particle swarm optimization. IET Gener. Transm. Distrib. 2011, 5, 1042-1052.

18. Park, J.B.; Jeong, Y.W.; Shin, J.R.; Lee, K.Y. An improved particle swarm optimization for nonconvex economic dispatch problems. IEEE Trans. Power Syst. 2010, 25, 156-166.

19. Shi, Y.; Eberhart, R. Empirical Study of Particle Swarm Optimization. In Proceedings of the 1999 Congress on Evolutionary Computation (CEC 99), Washington, DC, USA, 6-9 July 1999; Volume 3, pp. 1945-1950.

20. Coelho, L.S.; Mariani, V.C. Combining of chaotic differential evolution and quadratic programming for economic dispatch optimization with valve-point effect. IEEE Trans. Power Syst. 2006, 21, 989-996.

21. Meng, K. Quantum-inspired particle swarm optimization for valve-point economic load dispatch. IEEE Trans. Power Syst. 2010, 25, 215-222.

22. Alsumait, J.S.; Sykulski, J.K. A hybrid GA-PS-SQP method to solve power system valve-point economic dispatch problems. Appl. Energy 2010, 87, 1773-1781.

23. Chaturvedi, K.T.; Pandit, M.; Srivastava, L. Self-organizing hierarchical particle swarm optimization for nonconvex economic dispatch. IEEE Trans. Power Syst. 2008, 23, 1079-1087.

24. Selvakumar, A.I.; Thanushkodi, K. A new particle swarm optimization solution to nonconvex economic dispatch problems. IEEE Trans. Power Syst. 2007, 22, 42-51.

25. Lu, H.Y. Experimental study of a new hybrid PSO with mutation for economic dispatch with non-smooth cost function. Electr. Power Energy Syst. 2010, 32, 921-935.

26. Vlachogiannis, J.K.; Lee, K.Y. Economic load dispatch-A comparative study on heuristic optimization techniques with an improved coordinated aggregation-based PSO. IEEE Trans. Power Syst. 2009, 24, 991-1001.

27. Selvakumar, A.I.; Thanushkodi, K. Anti-predatory particle swarm optimization: Solution to nonconvex economic dispatch problems. Electr. Power Syst. Res. 2010, 78, 2-10.

28. Wang, S.K.; Chiou, J.P.; Liu, C.W. Non-smooth/non-convex economic dispatch by a novel hybrid differential evolution algorithm. IET Gener. Transm. Distrib. 2007, 1, 793-803.

29. Lee, K.Y.; Sode-Yome, A.; Park, J.H. Adaptive hopfield neural networks for economic load dispatch. IEEE Trans. Power Syst. 1998, 13, 519-525.

30. Cai, J.J.; Li, Q.; Li, L.X.; Peng, H.P.; Yang, Y.X. A fuzzy adaptive chaotic ant swarm optimization for economic dispatch. Electr. Power Energy Syst. 2012, 34, 154-160. 
31. Cai, J.J.; Li, Q.; Li, L.X.; Peng, H.P.; Yang, Y.X. A hybrid CPSO-SQP method for economic dispatch considering the valve-point effects. Energy Convers. Manag. 2012, 53, 175-181.

32. Wang, Y.; Li, B.; Weise, T. Estimation of distribution and differential evolution cooperation for large scale economic load dispatch optimization of power systems. Inf. Sci. 2010, 180, 2405-2420.

33. Amjady, N.; Nasiri-Rad, H. Nonconvex economic dispatch with AC constraints by a new real coded genetic algorithm. IEEE Trans. Power Syst. 2009, 24, 1489-1502.

34. Khamsawang, S.; Jiriwibhakorn, S. DSPSO-TSA for economic dispatch problem with nonsmooth and noncontinuous cost functions. Energy Convers. Manag. 2010, 51, 365-375.

(C) 2012 by the authors; licensee MDPI, Basel, Switzerland. This article is an open access article distributed under the terms and conditions of the Creative Commons Attribution license (http://creativecommons.org/licenses/by/3.0/). 